\title{
CARACTERIZAÇÃO ALIMENTAR DA Athene cunicularia (STRIGIFORMES: STRIGIDAE) (CORUJA BURAQUEIRA)
}

\section{CHARACTERIZATION OF FOOD Athene cunicularia (STRIGIFORMES: STRIGIDAE) (BURROWING OWL)}

\author{
Divaney Mamédio dos Santos ${ }^{1^{*}}$ \\ Verena Lima Cordeiro ${ }^{2}$ \\ Claus Burgos Cardoso ${ }^{2}$ \\ Maria Vanderly Andrea ${ }^{2}$ \\ Elinsmar Vitoria Adorno ${ }^{2}$ \\ Kaliane Nascimento de Oliveira ${ }^{1}$ \\ 1Universidade Estadual de Maringá, Maringá, PR, Brasil \\ 2Universidade Federal do Recôncavo da Bahia, Cruz das Almas, BA, Brasil. \\ *Autor para correspondência - divaneymds@yahoo.com.br
}

\section{Resumo}

O objetivo da proposta foi caracterizar a dieta alimentar da Athene cunicularia pela análise dos egagrópilos (regurgitos) em 15 tocas mapeadas em 10 hectares do campus da UFRB em Cruz das Almas, Bahia. Os regurgitos foram submetidos a tratamentos para a identificação da lista de cada item (vertebrados, invertebrados, material vegetal e pedras). Em seguida, foram submetidas a tratamentos para a identificação dos itens presentes. As análises revelaram que a alimentação das corujas foi composta de folhas, gravetos, sementes e muitos coleópteros scarabaeidae e ossículos do lagarto Ameiva ameiva, bem como a presença de sapos (Bufo sp.) sem cabeça e fragmentos ósseos de roedores (Mus musculus, Rattus norvegicus e Rattus rattus). Esta alimentação variou em virtude da influência de maior ou menor presença de pessoas nas áreas das tocas. Pela observação das atitudes comportamentais, é possível notar que os pais tenham demostrado ações de proteção em relação aos filhos e às tocas, através da emissão de sons e sobrevoos próximos aos invasores.

Palavras-chave: Alimentação; aves silvestres; preservação ambiental; regurgito.

\begin{abstract}
The aim of the proposal was to characterize the diet of Athene cunicularia by analysis of bezoars (regurgitation) in 15 burrows mapped in 10 acres campus UFRB in Cruz das Almas, Bahia. The regurgitations were subjected to treatments for identifying the percentage of each list item (vertebrates, invertebrates, plant material and stones). They were then subjected to treatments for identifying of items present. The analysis revealed that the feeding owls were composed of leaves, twigs, seeds, and many beetles and scarabaeidae lizard ameiva ossicles, and the presence of frogs (Bufo sp.) Without head and bone fragments rodents (Mus musculus, Rattus norvegicus and Rattus rattus). This power is varied under the influence of greater or lesser presence of people in the areas of the holes. By observation of behavioral attitudes, you can see that the parents have demonstrated
\end{abstract}


protective action in relation to cub and burrows through the emission of sounds and overflights near the invaders.

Keywords: Environmental preservation; food; regurgitos; wild birds.

Recebido em: 06 de junho de 2013

Aceito em 18 de agosto de 2017

\section{Introdução}

As corujas são aves de rapina, representantes da ordem Strigiformes, compreendendo duas famílias: Tytonidade e Strigidae. Dentro desta família, destaca-se a Athene cunicularia, que no Brasil é encontrada em campos abertos, pastagens, restingas, savanas e gramados de áreas urbanas e em quase todo território brasileiro, sendo comuns nas cidades, sobre cercas e fios ${ }^{(1,2)}$.

A A. cunicularia é conhecida popularmente como Coruja Buraqueira, e se destaca pela proximidade com o homem e adaptação ao meio urbano ${ }^{(3,4)}$. Encontra-se difundida desde a Terra do Fogo (Argentina) até o Canadá. Possui hábitos diurnos e crepusculares, ora com atividade noturna, o que a diferencia de outros membros da sua família, em que as atividades ocorrem somente à noite ${ }^{(1)}$.

A A. cunicularia é uma espécie generalista, que consome presas em função de sua disponibilidade ${ }^{(5)}$, característica esta que pode facilitar sua sobrevivência em cidades, onde normalmente há menor variedade de recursos alimentares. Alimenta-se de pequenos animais, principalmente roedores, morcegos, répteis, anfíbios, insetos e pequenas aves. No Brasil grande parte de sua dieta é constituída de invertebrados, principalmente de insetos ${ }^{(1)}$.

Segundo Motta-Junior ${ }^{(6)}$, a Coruja Buraqueira é uma espécie insetívora em relação à quantidade de presas consumidas. Em relação à biomassa, a espécie é classificada como predadora predominantemente de pequenos roedores (carnívora). Uma característica da digestão nas corujas é a coalizão dos restos não digeridos de presas em pelotas denominadas egagrópilos ou pelotas, regurgitadas pelo animal após sua formação.

Os regurgitos são compostos por ossos, anexos epidérmicos, exoesqueletos de invertebrados e de outras partes que não são digeridas ${ }^{(7)}$. Por não possuírem papo, a formação de pelotas é uma necessidade vital para sua sobrevivência. Portanto, as partes não digeríveis dos animais consumidos não são defecadas e sim regurgitadas ${ }^{(6)}$. Logicamente, as corujas também defecam e excretam ácido úrico, como toda ave, e suas fezes são compostas essencialmente de restos orgânicos não absorvidos na digestão. No final de cada dia e/ou durante a noite as corujas normalmente regurgitam de uma a duas pelotas, representando a noite/madrugada anterior de caça ${ }^{(6)}$.

A Coruja Buraqueira consome uma grande variedade de presas de vários níveis tróficos e quase não é predada, sendo o homem seu maior inimigo. Nesse sentido, estudos sobre a ecologia alimentar desses organismos são importantes e de grande valor para o entendimento das relações de transferência de energia em diferentes ecossistemas. Os estudos das dietas desses predadores são ainda valiosos para a aquisição e complementação de dados sobre a distribuição de muitas espécies, 
em especial pequenos mamíferos. Apesar disto, poucos estudos sobre estas foram realizados nas regiões tropicais ${ }^{(8)}$. Outro aspecto importante diz respeito ao comportamento das corujas com relação à presença humana nas proximidades das tocas.

Alguns aspectos da morfologia e biologia da espécie já foram relatados ${ }^{(9-11)}$, entre eles o comportamento de alarme ${ }^{(12)}$, preferência da $\operatorname{dieta}^{(13-15)}$, estudos dos egagrópilos ${ }^{(16)}$ e ninhos. No Brasil, a dieta dessa espécie já foi razoavelmente estudada ${ }^{(6)}$ e seu repertório alimentar é bastante amplo, incluindo desde artrópodes e pequenos vertebrados como roedores, aves, anuros, lagartos ${ }^{(6)}$.

A maior causa do declínio das populações é a degradação do seu ambiente natural, principalmente espécies florestais de grande porte. As corujas são predadores e, portanto, mais sensíveis às mudanças ambientais do que animais que ocupam outras posições (herbívoros, por exemplo) na cadeia alimentar. Segundo Martins e Egler ${ }^{(17)}$, a coruja buraqueira é um predador generalista de artrópodes e pequenos vertebrados, alimentando-se de qualquer espécie destes grupos, além de sua disponibilidade em seu habitat. Esta característica pode facilitar sua sobrevivência em locais com menor variedade de recursos alimentares ${ }^{(5)}$.

Surge a importância de aumentar os estudos sobre estas aves. Aspectos de sua ecologia carecem de mais estudos. Visando o conhecimento da biologia da espécie para contribuir com a preservação, o trabalho objetivou a caracterização alimentar de A. cunicularia no campus da Universidade Federal do Recôncavo da Bahia, em Cruz das Almas.

\section{Material e Métodos}

O estudo foi desenvolvido na Universidade Federal do Recôncavo da Bahia (UFRB), no Centro de Ciências Agrárias, Ambientais e Biológicas (CCAAB), Campus Universitário de Cruz das Almas, $12^{\circ} 40^{\prime} 19^{\prime \prime}$ de Latitude Sul, 39 06' 23" de Longitude Oeste de Greenwich e Altitude média de 220 m. O clima da região é considerado tropical quente e úmido, com pluviosidade média de $1170 \mathrm{~mm}$ e variações entre 800 e $1400 \mathrm{~mm}$, sendo os meses de março a agosto os mais chuvosos e de setembro a fevereiro, os mais secos. A temperatura média anual é de $24,5^{\circ} \mathrm{C}$ e umidade relativa de $80 \%{ }^{(18)}$.

As coletas de dados foram efetuadas em 10 hectares da UFRB, campus universitário de Cruz das Almas, considerando que a área de estudo (A1) era constituída em algumas partes, por grande fluxo de pessoas, carros e trabalhadores envolvidos na construção para implantação da nova Universidade, compreendendo, portanto, o espaço mais urbanizado da UFRB. Esta área envolve grandes prédios de aulas, laboratórios, prédios da administração, residências universitárias e escola primária do município. Apresenta vegetação composta por pastagens formadas por Brachiaria sp, sendo que em alguns lugares, estão em estágio avançado de degradação, além de um lote com aproximadamente um hectare de Eucalipto do gênero Citrodora e árvores de grandes portes.

A outra área (A2) envolve os setores zootécnicos de criação de animais de médio e grande porte (caprinos, ovinos, equídeos e bovinos) e menor fluxo de pessoas e carros. Apresenta como vegetação local, pastagens compostas por Brachiaria decumbens e B. humidicula. 
Inicialmente, foram mapeadas as duas áreas para identificação das tocas ativas e inativas das Corujas Buraqueiras no campus. As tocas foram marcadas e numeradas sequencialmente com uso de placas de madeira de $50 \mathrm{~cm}$ de altura, fixadas a $50 \mathrm{~cm}$ da entrada da toca. No mapeamento foram observados os seguintes itens: número de tocas ativas e inativas, medida do diâmetro da entrada (largura e altura), bem como forração (substrato das tocas) e número de animais por categoria de idade presentes no grupo familiar e sexo (através do tamanho, machos maiores e fêmeas menores e mais escuras). Para a realização do trabalho, foram selecionadas 15 tocas ativas para o acompanhamento das atividades, sendo dez tocas ativas na área 1 e cinco tocas ativas na área 2 . A dificuldade de acesso à área 2 pode ter interferido na localização das tocas, justificando menor número descrito.

O trabalho envolveu a caracterização da dieta alimentar da Coruja Buraqueira pela análise dos egagrópilos ou pelotas, segundo metodologia proposta ${ }^{(7)}$. Inicialmente, as tocas foram visitadas diariamente para coleta das pelotas, entretanto, estas não foram encontradas com esta frequência, optando-se assim por coletas semanais (uma hora no início manhã e uma hora no fim da tarde). As coletas foram realizadas semanalmente nas tocas mapeadas, no período de seis meses (de setembro de 2010 a fevereiro de 2011), correspondendo ao período seco da região, totalizando 128 amostras. O material coletado foi colocado dentro de coletores plásticos com tampa e imediatamente levados para o laboratório e acondicionados em geladeira até o momento das análises.

No laboratório as "pelotas" foram medidas (diâmetro e comprimento) utilizando paquímetro (Digimess 100.174BL) e em seguida, ainda em estado natural, eram pesados em balança analítica 0,001 g de precisão (Marte AL $500 \mathrm{C}$ ), embalados individualmente e anotada a sua procedência, (número e local da toca). Em seguida, foram tratados com $\mathrm{NaOH}$ a $10 \%$ durante 8 horas, secos em estufa a $60 \%$ por 48 horas e novamente pesados e armazenados. Cada unidade amostral representada por uma pelota regurgitada foi observada em lupa (Olympus S251) e devidamente identificada. Não foram feitas avaliações sobre a origem dos egagrópilos quanto à categoria familiar.

Nos mesmos horários e frequências das coletas, foram registradas algumas informações visuais sobre o comportamento no que se refere à vocalização de alerta, movimento de adultos e filhotes, proteção das tocas quanto à presença de humanos e outras espécies, porém não foi utilizado um etograma específico para este fim.

\section{Resultados e Discussão}

As atividades humanas podem causar prejuízos às populações das corujas no campus da UFRB, seja na destruição das tocas em virtude das construções e, provavelmente, na supressão dos habitats, interferindo na disponibilidade de recursos alimentares. Durante o período de execução do trabalho, várias vezes foram encontradas tocas fechadas com garrafas de refrigerantes impedindo o trânsito de filhotes e pais, levando-os à morte. É possível que o programa de expansão do campus UFRB Cruz das Almas e a presença de crianças oriundas de um Colégio Municipal presentes na área da Universidade esteja impactando as populações de A. cunicularia, espécie comum na região. A Coruja Buraqueira é uma espécie que quase não tem predadores naturais, sendo que a destruição do seu 
habitat, pelo homem, aparece como a principal ameaça à sobrevivência da espécie ${ }^{(1)}$.

Os resultados encontrados neste estudo confirmam os relatos de Jones e Bock ${ }^{(19)}$ e Chipman et al. ${ }^{(3)}$ que sugerem que as atividades humanas têm causado a degradação do habitat da coruja.

As corujas foram observadas nos períodos das manhãs e tardes, pousadas em campos abertos com pequenos arbustos, em áreas de pastagem, em estacas ou árvores próximas às tocas, sendo que estes locais de pouso muitas vezes encontravam-se localizados entre as construções, prédios da UFRB. Beebe et al. ${ }^{(20)}$, em estudos sobre o habitat da coruja, observaram as aves usando estruturas, vegetação e o solo como poleiros.

Segundo Motta-Junior ${ }^{(6)}$, esta espécie apresenta-se mais conspícua, facilmente localizada em campos e pastos abertos, utilizando quase sempre tocas de tatus como ninho e mourões de cerca, cupinzeiros e até o solo como poleiros. Estas consistem em um túnel que termina em uma câmara de ovipostura, geralmente forrada de capim, esterco ou mesmo restos de papel e outros resíduos encontrados em ambiente urbano $^{(12)}$. Devido à perda de habitat e a fragmentação do desenvolvimento agrícola e urbano, as corujas vivem muitas vezes em estreita proximidade com os seres humanos, mas muito pouco se sabe sobre seleção de habitat ${ }^{(20)}$ ou como seu comportamento é afetado pela proximidade ao ser humano ${ }^{(21)}$.

Estudos em que foram comparados diferentes habitat de corujas buraqueiras constataram que, em ambientes agrícolas, estes animais conseguem manter uma maior densidade de ninhos ${ }^{(22,23)}$, além de ser constatado que a urbanização demonstra um efeito negativo quanto à densidade populacional destas aves ${ }^{(4,20)}$.

Nas duas áreas de estudo foi observado que alguns pontos apresentaram falhas na cobertura vegetal, o que facilitou a fixação das corujas através da construção de tocas. Segundo Sick ${ }^{(1)}$, esta espécie prefere áreas de pastagens degradadas, construindo seus ninhos próximos aos cupinzeiros em áreas urbanas.

A média da largura na área 1 foi de $37 \mathrm{~cm}$ e a altura de 22,44 cm, na área 2 a média da largura foi de $43,3 \mathrm{~cm}$ e a altura de $28,16 \mathrm{~cm}$, demonstrando que a área que sofreu menos interferência urbana apresentou medidas de abertura das tocas maiores que na área mais urbanizada. Não foram realizadas análises de relação entre tamanho das tocas com o número de indivíduos por toca.

Foi observado ao longo deste estudo que a coruja buraqueira apresenta o costume de coletar uma diversidade de materiais para revestir o seu ninho, além de deixá-los ao redor da entrada da toca. Os materiais encontrados foram: área 1) penas, capim seco, estrumes de bovinos e equinos e área 2) capim seco, penas, estrumes e anfíbios secos. Lima ${ }^{(24)}$ menciona que estrumes servem como atrativos de coleópteros que os utilizam para postura, sendo estes são utilizados como alimento pelas corujas. O hábito de forrar o chão do ninho com restos de pelotas e alimento possui grande importância na manutenção da espécie, pois tem a função de acomodar os ovos e os futuros filhotes ${ }^{(8)}$. Podem também utilizar folhas secas, vegetação ou esterco seco para forrar o ninho.

Os egagrópilos coletados no campo "in natura" apresentaram uma variação de tamanho entre 1,5 a $3,0 \mathrm{~cm}$, sendo que a altura variou de 0,8 a 1,1 nas duas áreas, com peso médio de 2,67 e 3,3 g, respectivamente, para área 1 e 2 . Na Tabela 1 , encontram-se as informações referentes à frequência de coletas (de setembro a fevereiro) com os respectivos pesos e materiais encontrados. 
Tabela 1. Frequência, peso e materiais encontrados nos egagrópilos durante os meses de coletas.

\begin{tabular}{cccccc}
\hline Mês & $\mathbf{N}^{\circ}$ de Coletas & Peso $(\mathbf{g})$ & \multicolumn{3}{c}{ Material Encontrado (\%) } \\
\hline & & & Coleópteros & $\begin{array}{c}\text { Coleópteros, ossos e } \\
\text { outros }\end{array}$ & Ossos \\
\cline { 3 - 6 } Set & 27 & $1,03-6,14$ & 48,14 & 48,14 & 3,7 \\
Out & 20 & $1,20-5,79$ & 30,00 & 35,00 & 35,00 \\
Nov & 16 & $2,32-6,48$ & 31,25 & 56,25 & 12,25 \\
Dez & 19 & $1,98-5,32$ & 41,10 & 31,57 & 26,31 \\
Jan & 23 & $1,37-7,02$ & 21,73 & 60,86 & 17,39 \\
Fev & 13 & $1,32-4,76$ & 46,15 & 38,46 & 15,38 \\
\hline
\end{tabular}

Após os tratamentos realizados nos egagrópilos, as análises revelaram que a alimentação das corujas era composta principalmente de folhas, gravetos, sementes, ossículos de lagartos Ameiva ameiva e muitos besouros (coleópteros Scarabaeidae) na área 1 e os mesmos elementos acrescidos de ossos de aves, de roedores (Mus musculus, Rattus norvegicus e Rattus rattus) e anfíbios (Bufo sp), na área 2. A presença dos coleópteros justifica-se pela quantidade de estrumes existentes nas tocas. MottaJunior $^{(6)}$ e Vieira e Teixeira ${ }^{(15)}$ verificaram em suas pesquisas que este foi o item alimentar mais importante da dieta durante as estações seca e chuvosa. Ressaltando que a composição da dieta alimentar está relacionada à disponibilidade dos alimentos próximos aos locais de nidificação.

Estudos realizados por Andrade et al. ${ }^{(25)} \mathrm{e} \mathrm{Zilio}^{(5)}$ demonstram que os roedores também são alimentos importantes na dieta das corujas. Este hábito alimentar é de grande utilidade para o homem, uma vez que colabora para o controle da densidade populacional de roedores nas cidades, além de pragas em áreas agricultáveis. A. cunicularia é uma espécie generalista, que consome presas em função de sua disponibilidade $^{(5)}$, característica que pode facilitar sua sobrevivência em cidades, onde normalmente há menor variedade de recursos alimentares.

A atividade preferencial de caça varia em diferentes regiões, dependendo da disponibilidade da presa $^{(15)}$. As presas ingeridas por A. cunicularia nos locais de estudo provavelmente foram capturadas no período noturno, já que esta coruja mostra um aumento da atividade de caça no crepúsculo e noturno $^{(6)}$.

Durante as coletas das pelotas, foi possível também observar alguns padrões comportamentais. Foi visto que as corujas ficavam próximas às tocas e muito atentas às mesmas, em repouso sobre apenas uma perna em situações em que não se sentia ameaçada ou vocalizando avisos de som forte e estridente de forma praticamente ininterrupta a qualquer sinal de perigo e a aproximação de algum predador, conforme Jacobucci ${ }^{(12)}$. De maneira geral, a presença de várias tocas próximas ocupadas por uma mesma família foi um fato que chamou a atenção. Uma toca era usada para a postura dos ovos, as demais tocas eram utilizadas como ponto de fuga e dispersão dos indivíduos, quando estavam na presença de espécies diferentes "intrusos".

Os machos foram vistos na maior parte do tempo a alguns metros de distância da toca vigiando os filhotes, enquanto as fêmeas forrageavam a procura de alimento. Os filhotes foram observados vocalizando em direção aos pais, um som mais grave e baixo, quando não eram vistos por eles, e ao escutarem o sinal de alerta entravam no ninho permanecendo nele até o perigo se afastar como descrito por Jacobucci ${ }^{(12)}$. 
$\mathrm{Na}$ área 1, a aproximação de Vanellus chilensis (quero-quero) ou qualquer outro animal, perto da toca, provocava nos filhotes movimentos de rotação com a cabeça (intimidação). Entretanto, não apresentaram tal comportamento durante a passagem de humanos e veículos, desde a uma distância de aproximadamente 10 metros. Tal comportamento pode ser explicado pelo fato de as tocas se encontrarem nas proximidades de salas de aulas, onde transitam por dia muitas pessoas, não se sentindo ameaçado pela presença humana.

Entretanto, este mesmo comportamento não foi observado na área 2, onde ocorre um menor fluxo de pessoas, não sendo tolerável aproximação humana a menos de 15 metros. As corujas vivem muitas vezes em estreita proximidade com os seres humanos, mas muito pouco se sabe sobre como seu comportamento é afetado pela proximidade ao ser humano ${ }^{(26)}$.

\section{Conclusões}

Os componentes alimentares da Coruja Buraqueira nas duas áreas estudas no campus da UFRB variaram em virtude da disponibilidade alimentar próxima as áreas de nidificação, tendo a presença acentuada de roedores na área 2 , devido ao armazenamento de ração animal próximo às tocas. $\mathrm{Na}$ análises dos egagrópilos a participação de coleópteros Scarabeídeos em grande quantidade deve-se ao hábido destes de postura em estrume localizados dentro das tocas. A presença de penas e ossos revelam uma predação ativa de pequenos vertebrados.

Pela observação das atitudes comportamentais, é possível notar que os pais tenham demostrado ações de proteção em relação aos filhos e às tocas, através da emissão de sons e sobrevoos próximos aos invasores. No entanto, são necessárias maiores observações para ratificar estes achados. Em relação à presença humana, notou-se que na área 1, mais urbanizada, as corujas não desempenharam qualquer atitude agressiva, sendo notada característica antogônica na área 2.

\section{Referências}

1. Sick H. Ornitologia brasileira. 2a ed. Rio de Janeiro: Editora Nova Fronteira; 1997. 912 p.

2. Höfling E, Camargo HFA. Aves no Campus. 3ª ed. São Paulo: Edusp e IBUSP; 2002. 168 p.

3. Chipman ED, McIntyre NE, Strauss RE, Wallace MC, Ray JD, Boal CW. Effects of human land use on western Burrowing Owl foraging and activity budgets. Journal of Raptor Research. 2008;42(2):87-98.

4. Berardelli D, Desmond MJ, Murray L. Reproductive success of Burrowing Owls in urban and grassland habitats in southern New Mexico. The Wilson Journal of Ornithology. 2010;122(1):51-59.

5. Zilio F. Dieta de Falco sparverius (Aves: Falconidae) e Athene cunicularia (Aves: Strigidae) em uma região de dunas no sul do Brasil. Revista Brasileira de Ornitologia. 2006;14(4):379-392.

6. Motta-Junior JC. Relações tróficas entre cinco Strigiformes simpátricas na região central do Estado de São Paulo, Brasil. Revista Brasileira de Ornitologia. 2006;14(4):359-377. 
7. Motta-Junior JC, Alho CJR. Corujas: o que elas comem? Ciênciahoje.1998;23(136):60-62.

8. Motta-Junior JC. Ecologia alimentar de corujas (Aves: Strigiformes) na região central do Estado de São Paulo: biomassa, sazonalidade e seletividade de suas presas [Tese]. São Carlos: Universidade Federal de São Carlos; 1996. 177 p.

9. Rodríguez-Estrella R, Ortega-Rubio A. Nest site characteristics and reproductive success of Burrowing owls (Strigiformes: Strigidae) in Durango, Mexico. Revista de Biología Tropical. 1993;41(1):143-148.

10. Marks JS, Cannings RJ, Mikkola H. Family Strigidae (Typical Owls). In del Hoyo J, Elliot A, Sargantal J, eds. The Handbook of Birds of the World - Volume 5. Barcelona: Lynx Edicions; 1999.

11. Millsap BA, Bear C. Density and reproduction of Burrowing owls along an urban gradient. Journal of Wildlife Management. 2000;64(1):33-41.

12. Jacobucci GB. Comportamento de alarme em corujas buraqueiras (Athene cunicularia) durante o período reprodutivo no sudeste do Brasil. Revista Brasileira de Zoociências. 2007;9(2):145-150.

13. York MM, Rosenberg DK, Sturm KK. Diet and food-niche breadth of Burrowing Owls (Athene cunicularia) in the Imperial Valley, California. Western North American Naturalist. 2002;62(3):280-287.

14. Nabte MJ, Pardin UJF, Saba SL. The diet of the Burrowing Owl, Athene cunicularia, in the arid lands of northeastern Patagonia, Argentina. Journal of Arid Environments. 2008;72(8):1526-1530.

15. Vieira LA, Teixeira RL. Diet of Athene cunicularia (Molina, 1782) from a sandy coastal plain in southeast Brazil. Boletim do Museu de Biologia Mello Leitão. 2008;23(5):5-14.

16. Bastian MAS, Fraga ED, Mäder A, Garcia AS, Sander M. Análise de egagrópilas de coruja buraqueira, Athene cunicularia (MOLINA, 1782) no Campus da UNISINOS, São Leopoldo - RS (Strigiformes: Strigidae). Revista Biodiversidade Pampeana. 2008;6(2):70-73.

17. Martins M, Egler SG. Comportamento de caça em um casal de corujas buraqueiras (Athene cunicularia) na região de Campinas, São Paulo, Brasil. Revista Brasileira de Biologia. 1990;50(32):579-584.

18. Belthoff JR, King RA. Nest-site characteristics of Burrowing Owls (Athene cunicularia) in the Snake River Birds of Prey National Conservation Area, Idaho, and applications to artificial burrow installation. Western North American Naturalist. 2002;62(1):112-119.

19. Jones ZF, Bock CE. Conservation of grassland birds in an urbanizing landscape: a historical perspective. The Condor. 2002;104(3):643-651.

20. Beebe SR, Switalski AB, Bateman HL, Hristovski KD. Burrowing owl (Athene cunicularia) habitat associations in agriculture fields and along canal trails in Phoenix, Arizona. Journal of the Arizona-Nevada Academy of Science. 2014;45(2):52-58.

21. Gervais JA, Rosenberg DK, Anthony RG. Space use and pesticide exposure risk of male burrowing owls in an agricultural landscape. Journal of Wildlife Management. 2003;67(1):155-164.

22. Conway CJ, Garcia V, Smith MD, Ellis LA, Whitney JL. Comparative demography of Burrowing Owls in agricultural and urban landscapes in southeastern Washington. Journal of Field Ornithology. 2006;77(3):280290.

23. Moulton CE, Brady RS, Belthoff JR. Association between wildlife and agriculture: underlying mechanisms and implications in Burrowing Owls. Journal of Wildlife Management. 2006;70(3):708-716.

24. Lima PC. Comportamento reprodutivo da coruja buraqueira Athene cunicularia grallaria (Temminck, 1822) em um encrave de cerrado no Litoral Norte da Bahia. Atualidades Ornitológicas. 2007;135(1):12-13. 
25. Andrade A, Sauthier DEU, Pardinas UFJ. Vertebrados depredados por La Lechucita Vizcachera (Athene cunicularia) en La Meseta de Somuncurá (Río Negro, Argentina). Hornero. 2004;19(2):91-93.

26. Temeles EJ. The effect of prey consumption on territorial defense by harriers: differential responses to neighbors versus floaters. Behavioral Ecology and Sociobiology. 1989;24(4):239-243. 